Instructions for authors, subscriptions and further details:

http://brac.hipatiapress.com

\title{
Los Qualia y la Experiencia de la Consciencia en el Arte Belén León-Río ${ }^{1}$
}

1) Departamento de Escultura e Historia de las Artes Plásticas, Facultad de Bellas Artes, Universidad de Sevilla.

Date of publication: June $3^{\text {rd }}, 2021$

Edition period: June 2021 - October 2021

To cite this article: León-Río, B. (2021). Los Qualia y la Experiencia de la Consciencia en el Arte. Barcelona, Research, Art, Creation, 9(2), pp. 185213. doi: $10.17583 /$ brac.2021.4332

To link this article: http://dx.doi.org/10.17583/brac.2021.4332

\section{PLEASE SCROLL DOWN FOR ARTICLE}

The terms and conditions of use are related to the Open Journal System and to Creative Commons Attribution License (CC-BY). 
BRAC - Barcelona Research Art Creation. Vol. 9 No. 2, June 2021, pp. $185-213$

\section{The Qualia and the Experience of Consciousness in Art}

Belén León-Río

Departamento de Escultura e Historia de las Artes Plásticas, Facultad de Bellas Artes. Universidad de Sevilla.

(Received: 25 March 2019; Accepted: 13 April 2021; Published: 3 June 2021)

\section{Abstract}

Our life would be surrounded by a universal property called qualia that would constitute the everyday qualities of existence that would encompass among other things our sensations, perceptions, feelings and intuitions so that we would experience the world in the form of qualia such as light, sound, color, the shape or texture. These qualities would give cohesion to our senses and would have an important role in the art world to be closely linked to our subjective world.

In this article we will see how our consciousness would create reality manifesting itself in art through various perceptual experiences related to a qualia network where introspection, intuition, imagination, and creativity would also enter into a more subtle plane. The qualia would help the artist to project himself into everything he would experience, not only in the act of observing but also in the same artistic processes where emotions would be translated into symbols that would enhance our evolution, as the next leap we would make would have to do with our consciousness.

Keywords: Qualia, consciousness, reason, intuition, subjectivity, unconscious 
BRAC - Barcelona Research Art Creation. Vol. 9 No. 2, June 2021, pp. $185-213$

\section{Los Qualia y la Experiencia de la Consciencia en el Arte}

Belén León-Río

Departamento de Escultura e Historia de las Artes Plásticas, Facultad de Bellas Artes. Universidad de Sevilla.

(Recibido: 25 marzo 2019; Aceptado: 13 abril 2021; Publicado: 3 junio 2021)

\section{Resumen}

Nuestra vida estaría rodeada por una propiedad universal llamada qualia que constituiría las cualidades cotidianas de la existencia que abarcaría entre otras cosas nuestras sensaciones, percepciones, sentimientos e intuiciones de manera que experimentaríamos el mundo en forma de qualia como la luz, el sonido, el color, la forma o la textura. Estas cualidades darían cohesión a nuestros sentidos y tendrían un importante papel en el mundo del arte al estar estrechamente unidas a nuestro mundo subjetivo.

En este artículo veremos cómo nuestra consciencia crearía la realidad manifestándose en el arte mediante diversas experiencias perceptivas relacionadas con una red de qualia donde también entrarían en un plano más sutil la introspección, la intuición, la imaginación, y la creatividad. Los qualia ayudarían al artista a proyectarse en todo lo que experimentaría, no sólo en el acto de observar sino también en los mismos procesos artísticos donde las emociones se traducirían en símbolos que potenciarían nuestra evolución pues el siguiente salto que demos tendría que ver con nuestra consciencia.

Palabras clave: Qualia, consciencia, razón, intuición, subjetividad, inconsciente 


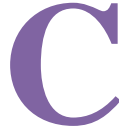

D. Chopra y M. C. Kafatos afirman como viviríamos en un mundo cuántico multidimensional donde nos proyectaríamos en todo lo que experimentamos no sólo en el acto de observar, sino que también participaríamos en la realidad que surge, de manera que nuestra percepción sería "un acto de participación en la realidad" (Chopra y Kafatos, 2017, p. 285). El ser humano experimentaría el mundo en forma de "qualia" que constituirían las cualidades cotidianas de la existencia, siendo "el aglutinante que da cohesión a los cinco sentidos" (Chopra y Kafatos, 2017, p. 287), como la luz, el sonido, el color, la forma o la textura, considerando estos autores como la realidad constaría de "estados variables e intercambiables" (Chopra y Kafatos, 2017, p. 299) que emanarían de una misma fuente: la consciencia" (Chopra y Kafatos, 2017, p. 299). Para D. Chopra y M. C. Kafatos el universo se basaría en la consciencia obedeciendo al mismo tiempo tanto a las leyes naturales como a nuestros pensamientos, llamando la atención de como la física cuántica habría demostrado como "el universo no tendría una base sólida, fija ni tangible” (Chopra y Kafatos, 2017, p. 328), por lo que estos autores han concluido basándose en estas premisas que todo esto nos llevaría a la "ciencia cuálica" introduciendo un término nuevo al que llaman "los qualia":

Los qualia se refieren al modo en que experimentamos la vida, más qué a cómo la medimos. La palabra qualia, que en latín significa "cualidades", designa un mundo tan extenso como el de la física cuántica, pero apunta en sentido opuesto: no a los objetos físicos, sino a la experiencia subjetiva. (Chopra y Kafatos, 2017, p. 286)

D. Chopra y M. C. Kafatos afirman como la subjetividad tendría gran importancia en el mundo de los qualia, llamando la atención de cómo en su terreno de juego disfrutaríamos "de una libertad creativa infinita" (Chopra y Kafatos, 2017, p. 289). Todo esto es aplicable igualmente al mundo del arte pues como decía C. G. Jung, cada creador tendría una imagen particular y distinta de reproducir la realidad debido a la influencia del factor subjetivo, como vemos en las obras de arte en las que se reproducirían objetos externos, de forma que si un mismo paisaje fuera pintado por diversos pintores que intentaran reproducirlo fielmente, comprobaríamos que las obras resultantes no serían iguales, no por la capacidad más o menos desarrollada de los distintos pintores, sino porque sus sensaciones se basarían 
preponderantemente en el componente subjetivo de la percepción, donde cada uno vería el paisaje distinto e incluso en alguna obra se puede manifestar "una pronunciada diversidad psíquica en la atmosfera y en el movimiento del color y de las figuras. Esas propiedades delatan una intervención más o menos fuerte del factor subjetivo" (Jung, 1994, p. 465). Miró decía sobre su forma de representar las cosas:

Pronto me di cuenta, que era necesario ir más allá del espíritu de miniatura; mucho más allá. Que era necesario permitir que el detalle se expandiera, para que se confundiese con el todo; para que la gente tuviera la sensación de que estaba allí, aun cuando no lo hubiera podido ver antes. (como se citó en Erben, 1998, p. 175)

E. R. Kandel señala como existiría "una gama universal de emociones que todas las personas pueden sentir, recordar y comunicar" (Kandel, 2014, p. 353), como ocurre con el arte moderno del siglo XX donde los artistas plásticos investigaron la manera de comunicar con el espectador a través de nuevas claves como exagerar sus realizaciones formales, distorsionar el color o el uso de nuevas iconografías, además de recurrir "al recuerdo de vivencias emocionales similares por parte del observador y a su capacidad de reconocer referentes históricos claros y de entender el significado de los símbolos" (Kandel, 2014, pp. 353-254). Los qualia estarían íntimamente relacionados con el arte al ser experiencias subjetivas donde entrarían no sólo nuestras percepciones, cogniciones, o efectos mentales, "como los sentimientos de amor, compasión, sufrimiento, hostilidad, placer sexual y éxtasis religioso" (Chopra y Kafatos, 2017, p. 289), sino que también entrarían en un plano más sutil la "introspección, intuición, imaginación, creatividad" (Chopra y Kafatos, 2017, p. 289).

Según D. Chopra y M. C. Kafatos la materia estaría “abarcada por la misma matriz que contiene los pensamientos y los sueños" (Chopra y Kafatos, 2017, p. 151), de manera que los qualia variarían en función del estado de nuestra consciencia, este hecho podemos constatarlo en las reflexiones de Paul klee sobre el color en su obra Teoría del arte moderno donde señala como el artista presentiría la creación, haciendo entrar las cosas en el movimiento de nuestra realidad haciéndolas visibles: "El iniciado presiente el punto original de vida. Posee algunos átomos vivientes, posee cinco pigmentos vivos: los elementos de la forma, y conoce un pequeño sitio gris de donde puede lograr el salto del caos al orden" (Klee, 2007, p. 54).

Sri Aurobindo relaciona la consciencia con la intuición, a la que define como "una consciencia-de-sí" que sentiría, percibiría y captaría su propia 
verdad, naturaleza, y poder directamente en su sustancia y en sus aspectos, en lugar de analizar sus mecanismos. Señalando como la sobremente o "mundo de los dioses" sería la cima de nuestra humanidad mental actual, siendo de allí, donde los artistas, poetas, místicos y grandes profetas sacan su inspiración o sus revelaciones, como vemos en el siguiente texto de Platón que Sri Aurobindo interpreta como una expresión mental del filósofo griego sobre la realización de la Sobremente:

El mundo de los sentidos es la copia del mundo de las Ideas. En nuestro mundo visible hay una gradación de los seres... Lo mismo es válido para el reino o esquema inteligible del mundo; las Ideas son unidas conjuntamente por otras Ideas de un orden superior... Las Ideas crecen continuamente en generalidad y fuerza hasta que se alcanza la cúspide, la última, la más alta, la Idea más poderosa: el Bien, que comprende, contiene o resume el sistema entero. (como se citó en Kiran, 2004, pp. 29-30)

Sri Aurobindo señala como a la sobremente le seguiría la supermente, el "mundo solar" de los Vedas, que sería el próximo paso de nuestra evolución. Esta ascensión a los primeros niveles no sería el final ya que nos quedarían planos todavía más elevados por descubrir en el mundo supramental como decían los antiguos poetas védicos: "Los sacerdotes de la palabra suben por ti como por una escalera, oh, tú, el de los cien poderes. A medida que se asciende de una a otra cima, se ve nítidamente lo mucho que queda por hacer" (como se citó en Aurobindo, 2002, p. 302). Para Sri Aurobindo el motivo principal de nuestra evolución sería la emergencia y crecimiento de la consciencia, esta evolución partiría desde el nivel más bajo en el inconsciente trabajando en el seno de la materia. La consciencia y no la vida y la forma constituiría el principio de nuestra evolución, aunque la vida y la mente serían peldaños e instrumentos de esta evolución donde el pensamiento puede ser utilizado "no como la mente, sino guiado por algo así como un instinto material inherente prácticamente infalible en todos sus pasos, todavía no cognitivo, pero milagrosamente creativo" (Aurobindo, 2004, p. 87). La poesía, el arte la filosofía y la organización perfecta de nuestra vida terrestre deben ser elevadas "y las posibilidades ya alcanzadas o cuales quiera perfección ya conseguida tienen que ser integradas en una perfección nueva y superior con una visión e inspiración más amplias de una consciencia espiritual y con nuevas formas y poderes" (Aurobindo, 2004, p. 19).

M. Kaku cree que, a pesar de todos los milagrosos avances en escáneres cerebrales y alta tecnología, muchos investigadores piensan que nunca 
entenderemos el secreto de nuestra consciencia, ya que estaría fuera del alcance de nuestros conocimientos científicos actuales a los que califica de deficientes. Para este autor la consciencia sería más fundamental que los átomos, las moléculas y las neuronas, siendo la entidad fundamental del universo, incluso por encima de los átomos: "El mundo material puede aparecer o desaparecer, pero la consciencia permanece como elemento definitorio. Eso significa que ésta última, en cierto sentido, crea la realidad." (Kaku, 2014, p. 429) M. Kaku llama la atención al respecto de cómo Eugene Wigner que estableció los cimientos de la mecánica cuántica concluyó como no se podía "formular las leyes (de la teoría cuántica) de una manera completamente consistente sin hacer referencia a la consciencia" (como se citó en Kaku, 2014, p. 429).

D. Chopra y M. C. Kafatos señalan como los qualia nos permitirían "conectar todo entre sí a través de una propiedad común. Todo es un aspecto de un campo único de la consciencia” (Chopra y Kafatos, 2017, p. 331). Diciendo como el dominio cuántico sería un plano más de los qualia, teniendo características mentales ya que nuestra mente adoptaría la apariencia de cuantos" (Chopra y Kafatos, 2017, p. 203). La física al entrar en el dominio de lo cuántico se habría introducido en el estado virtual y a pesar de que es invisible e intangible no por ello sería menos real, nombrando a autores como Von Neumann que afirma como la realidad tendría un componente psicológico, o el físico Max Planck que dice como: "Toda materia se origina y existe únicamente en virtud de una fuerza. Debemos suponer que tras esta fuerza existe una mente consciente e inteligente, esta mente es la matriz de toda la materia" (como se citó en Chopra y Kafatos, 2017, p. 151). También K. Korotkov relaciona nuestra consciencia con la electrodinámica cuántica, este autor partiría del concepto de la triple manifestación de la naturaleza humana que posibilitaría el paso de un modelo primitivo que concibe al individuo como una máquina biológica "a la noción del hombre como la quintaesencia del Espíritu Divino. De manera curiosa, estas ideas tienen paralelos directos con los conceptos científicos modernos, en particular, la teoría del campo cuántico" (Korotkov, 2015, p. 193). En la electrodinámica cuántica, la consciencia sería un efecto del sistema que no dependería de una parte particular del cuerpo, ni tan siquiera del cerebro, sino del sistema como un todo:

Podemos atribuir cierto nivel de conciencia a cada célula del organismo o a un órgano en particular, pero para lograr un alto nivel de conciencia necesitamos una actividad coordinada de todas las células, de todos los 
órganos. La electrodinámica cuántica opera con la noción de un sistema que consta de muchos elementos, por eso se puede aplicar a la construcción de la teoría de la consciencia. (Korotkov, 2015, p. 158)

\section{El Arte y los Qualia en los Procesos Perceptivos, Relacionados con la Creación y Recreación del Arte}

Nuestra experiencia del cuerpo y de nuestra actividad mental sería una experiencia qualica que los artistas investigan en sus creaciones. El artista Stahl Stensilie junto con Kirk Wofford recurrieron en 1994 a las nuevas tecnologías para experimentar con interfaces de realidad virtual para ello utilizaron el cuerpo humano como interfaz de dialogo a través del tacto, llegando Stahl a través de estas experiencias a concluir como el cuerpo sería:

[...] un objeto físico unitario e individual con una esperanza de vida de unos setenta años, y por otra ha dado un salto espectacular a un yo múltiple y trascendental de realidades mediatizadas. La cuestión ya no es qué o quién soy, sino lo que puedo llegar a ser. (como se citó en Warr y Jones, 2006, p. 188)

Para D. Chopra y M. C. Kafatos la mente humana tendría una aspiración de conocer la realidad mediante los qualia que abarcarían no sólo los cinco sentidos, sino también "las sensaciones, las imágenes, los sentimientos y los pensamientos de la mente" (Chopra y Kafatos, 2017, p. 300). Estos qualia serían subjetivos y tendrían que ver entre otras cosas con las sensaciones, sentimientos o pensamientos: "El aroma de una rosa es un quale (quale es el singular de qualia), como también son qualia la textura aterciopelada de sus pétalos, sus colores y matices, sus sombras y sus pliegues" (Chopra y Kafatos, 2017, p. 287). El color sería una manifestación de la consciencia y al ser qualia puede ser alterado por el estado de consciencia en que nos encontremos. N. Farouki llama la atención de como los científicos se encontrarían con numerosos interrogantes que tendrían que ver con nuestra existencia, preguntándose si esta realidad sería absoluta, en sí, o una mezcla entre una realidad desconocida y nuestras capacidades sensoriales:

El mundo, tal como lo vemos, no es una simple ilusión; evidentemente, depende mucho de nuestras percepciones (el color, por ejemplo, proviene de la luz; en sí misma, la naturaleza no está coloreada). Pero, globalmente, lo que dicen nuestros sentidos es un aspecto de la realidad de la que no se puede negar, en el marco de un método científico que 
confía plenamente en la observación, ni la existencia ni el valor.

(Farouki, 1994, pp. 94-95)

F. Wilczek dice que habría mujeres que podrían "discriminar entre mezclas de colores espectrales que la mayoría de la gente percibe como indistinguibles" (Wilczek, 2016, p. 163). Este autor señala como la mayoría del espectro electromagnético se escaparía a nuestra visión como ocurre con casi toda la radiación electromagnética que viene del Sol, ésta al penetrar la atmósfera se concentraría "cerca de la parte más útil a la que se pueden sintonizar las criaturas terrícolas. Es decir, es donde la señal se enciende" (Wilczek, 2016, p. 163). Admirándose de como la "entidad que percibiríamos como espacio vacío es un conductor de muchas capas y multicolor" (Wilczek, 2018, pp. 84-85).

Kandinsky decía que si paseamos los ojos por una paleta llena de colores podríamos obtener un efecto "puramente físico" y un efecto "psicológico" producido por la contemplación del color, aquí la impresión superficial del color se podría convertir en vivencia, la sensación física penetraría más adentro despertando sensaciones más profundas y provocando toda una serie de vivencias psicológicas: "Aquí aparece la fuerza psicológica del color, que provoca una vibración anímica. La fuerza física elemental es la vía por la que el color llega al alma" (Kandinsky, 2010, p. 52). E. H. Gombrich señala como el arte del siglo XX en su mayoría, se orientaría hacia la sinestesia ya que aspiraría a representar el mundo mental, mediante formas y colores que equivaldrían a emociones, diciendo como la mayoría de las personas experimentaría imágenes sinestesias con mayor o menor intensidad:

\begin{abstract}
¿No son completamente subjetivas y privadas, inaccesibles e incomunicables? ¿Pueden darse auténticos descubrimientos objetivos de concordancias buenas y mejores en tan huidizos dominios, cómo se daban en el descubrimiento de analogías visuales para la experiencia visual? (Gombrich, 2002, p. 311)
\end{abstract}

J. Itten en su obra El arte del color señala como cada color espectral se puede medir mediante el número de vibraciones o su longitud de onda, pero el color se generaría en el ojo y en el cerebro, ya que "las ondas luminosas en sí no tienen color" (Itten, 2020, p. 27). Este hecho sería un misterio, es decir como seriamos capaces de reconocer estas ondas: "Solo se sabe que cada color aislado nace de las diferentes cualidades de sensibilidad a la luz" (Itten, 2020, p. 27). Itten afirma como los efectos que produce el color deberíamos experimentarlos y comprenderlos no sólo ópticamente sino también de forma 
psíquica y simbólica, llamando la atención de como las formas y los colores reales de la materia tienen la capacidad de transformarse en vibraciones irreales lo que permitiría al artista "expresar algo impronunciable" (Itten, 2020, p. 30). El pintor además llamaba la atención de como en la actualidad se habría producido un gran interés por el color desde un punto de vista material y óptico como ocurre con la fotografía, la moda o la química del color, pero solo se trataría de "un juego externo y superficial con fuerzas metafísicas. Los colores son fuerzas de irradiación, energías que influyen en nosotros de forma positiva o negativa, seamos conscientes de ello o no" (Itten, 2020, pp. 19-20).

El filósofo australiano de la mente D. Chalmers afirma en su obra titulada The Conscious Mind: In Search of Fundamental Theory publicado en 1996 como habría una estrecha relación entre la consciencia y la cognición, diciendo qué si una persona tuviera una sensación de verde, esta sensación no sólo se individuaría como fenómeno, sino que tendría "una correspondiente percepción de verde, individuada psicológicamente" (como se citó en Fontcuberta Llavata, 2016, p. 122) Según este autor la consciencia surgiría del cerebro, aunque no se encontraría implicada por este sustrato físico diciendo al respecto: "El mismo hecho de que la mente necesite surgir del cerebro indica que hay algo adicional que está ocurriendo más allá de los hechos físicos." (como se citó en Fontcuberta Llavata, 2016, p. 146) D. Chalmers considera como nuestras sensaciones y experiencias se relacionarían con la vida interna de nuestra mente diciendo:

La experiencia consciente incluye desde las sensaciones vívidas de color hasta las experiencias de los aromas más tenues del ambiente; desde dolores agudos hasta la experiencia elusiva de tener un pensamiento en la punta de la lengua; desde sonidos y olores mundanos hasta la envolvente grandeza de la experiencia musical; desde la trivialidad de un picor molesto al peso de la profunda angustia existencial; desde la especificidad del sabor de la menta a la generalidad de la experiencia que uno tiene del yo. Todas estas cosas tienen una cualidad experimentada diferente. Todas son partes destacadas de la vida interna de la mente. (como se citó en Fontcuberta Llavata, 2016, p. 37)

Para D. Chalmers cuando tratamos con "los misterios filosóficos" que se asociarían con nuestra "experiencia consciente, una simple sensación de color plantea los problemas tan profundamente como la experiencia de uno al escuchar una coral de Bach" (como se citó en Fontcuberta Llavata, 2016, p. 
44). Según Chalmers entre estos estados mentales que abarca la experiencia consciente se encontrarían las experiencias sensitivas como las visuales relacionadas con el color, la forma, la profundidad, el brillo, etc. Las experiencias auditivas, que a diferencia de las anteriores "no parecen corresponderse con la estructura del mundo" (Fontcuberta Llavata, 2016, p. 43), destacando como estas experiencias, aunque se puedan descomponer en los sonidos, los tonos, las notas, etc., en conjunto producirían una experiencia cualitativa única, como ocurre con la música. También las sensaciones táctiles proporcionarían una gran variedad de experiencias dependiendo de las distintas texturas existentes, mientras que las sensaciones olfativas carecerían de estructura siendo por ello difícil de describir. Las sensaciones del gusto se generarían "a partir de un espacio de cuatro dimensiones: dulce, salado, amargo y agrio" (Fontcuberta Llavata, 2016, p. 44). Para Chalmers las imágenes mentales no solo serían las que tendrían que ver con la imaginación, sino también estarían los "fenómenos como las postimágenes que surgen después de mirar algo brillante, o los patrones de colores que pueden aparecer al cerrar los ojos. Chalmers señala que lo específico de este tipo de experiencias es que son generadas <internamente>" (Fontcuberta Llavata, 2016, p. 44).

D. Chalmers al igual que Blok, Loar y Peacoke defenderían según A. Arias Domínguez "la autonomía e irreductibilidad del ámbito de lo mental que los qualia conformarían" (Arias Domínguez, 2012, p. 32). A principios de los ochenta Frank Jackson en su artículo Epiphenomenal Qualia presentaría el argumento epistemológico de los qualia donde nos mostraría intuitivamente como la experiencia de nuestra consciencia no se basaría únicamente en contenidos proposicionales o conceptuales, dirigiendo acertadamente "nuestra intuición hacia la propiedad de los qualia según la cual los mismos son privados y están dotados de perspectiva" (Arias Domínguez, 2012, p. 47). Frank Jackson en este artículo refuta el fisicalismo "mediante el famoso experimento mental de Mary, la neurofisióloga del color forzada a una existencia acromática" (Arias Domínguez, 2012, p. 32), donde define los qualia como "ciertos rasgos de las sensaciones corporales y también de ciertas experiencias preceptuales inaprensibles a través del mero acopio de información física" (Arias Domínguez, 2012, p. 32). Esta idea sería la misma que expresa Itten cuando dice como los cálculos constructivos previos a la ejecución de la obra artística no determinarían la forma final ya que la "sensación intuitiva" estaría por encima de esta construcción previa, siendo realmente esta sensación analógica la que nos conduciría "al reino de lo irracional y lo metafísico, que no es posible comprender con ningún número. 
Las reflexiones intelectuales y constructivas son tan solo <el vehículo> que nos conduce hasta las puertas del nuevo ser" (Itten, 2020, p. 47).

Sri Aurobindo señala como el conocimiento que pueden procurarnos los sentidos y el razonamiento intelectual por los datos de los sentidos, no sería verdadero conocimiento, definiéndolo como "ciencia de las apariencias". Para este autor ni siquiera las apariencias pueden conocerse apropiadamente a menos que conozcamos primero la "Realidad" (Aurobindo, 1980a, p. 23) de la que serían imágenes: "Esta Realidad es su yo y hay un yo de todo; cuando se le capta, pueden entonces conocerse todas las otras cosas en su verdad y no ya como ahora, solo en su apariencia." (Aurobindo, 1980a, p. 23) Afirmando como en el mundo físico habría siempre dos formas de conocimiento que divide en la directa y la indirecta:

[...] pratyaksa, de lo que está presente ante los ojos, y paroksa, de lo que está lejos y más allá de nuestra visión, estamos obligados necesariamente a arribar a una idea de él por inferencia, imaginación, analogía, audición de descripciones de otros que lo vieron, estudio pictórico u otras representaciones de él si están a nuestro alcance. (Aurobindo, 1980a, p. 25)

Unificando todos estos auxilios podremos llegar a una idea más o menos adecuada o a una imagen sugestiva del objeto, pero no llegaríamos a captar la cosa en sí, es decir no lograríamos captar la realidad sino sólo nuestra representación conceptual de una realidad: "Pero una vez visto con los ojos pues ningún otro sentido es adecuado-, poseemos y comprendemos; nos afirma en nuestra satisfacción esencial, es parte nuestra en el conocimiento" (Aurobindo, 1980a, p. 25).

Joahannes Itten basándose en el "efecto ético-sensorial" del color de Goethe afirma como la contemplación de los colores generaría procesos ópticos, electromagnéticos y químicos en el cerebro y en el ojo que corresponderían frecuentemente "con procesos paralelos en el ámbito espiritual. Estas conmociones, originadas por la experiencia de las fuerzas cromáticas, pueden arraigarse hasta el mismísimo centro y alcanzar con ello regiones decisivas de la experiencia mental y espiritual" (Itten, 2020, p. 119). En este sentido el filósofo C. McGinn propone un "naturalismo transcendental" de los qualia diciendo como el cerebro tendría alguna propiedad que explicaría la consciencia, pero estaríamos cognitivamente cerrados a este conocimiento, para este autor la consciencia sería "un fenómeno natural, mejor conocido que cualquier otro: su existencia es un dato" (Pérez, 2002, p. 76). 
J. F. Correcher señala como C. McGinn sería conocido por sus reflexiones sobre filosofía de la mente, siendo su postura una continuación del misterianismo que defendía Locke, para el filósofo el ser humano no tendría capacidad para entender que conexiones existentes entre la mente y el cerebro ya que estaríamos limitados cognitivamente para entender este misterio sobre el cual girarían cuatro tipos de preguntas que designa como "problemas", "misterios", "ilusiones" y "cuestiones". Mientras que los problemas tendrían que ver con las preguntas que el individuo se hace desde un punto de vista de sus capacidades cognitivas sobre los fenómenos naturales, los misterios tratarían de preguntas de la misma naturaleza que los problemas, pero con la diferencia de que las respuestas a estas preguntas estarían fuera de nuestro alcance debido a nuestras limitaciones cognitivas, de esta manera un misterio puede serlo para un ser concreto, pero no para otros seres. Las preguntas sobre las ilusiones "serían pseudocuestiones y las cuestiones solo asuntos de carácter más bien normativo" (Correcher Valls, 2013, p. 82). Como vemos para C. McGinn la consciencia sería un fenómeno de carácter natural siendo un misterio que estaría fuera del alcance de nuestras capacidades como señala el filósofo: "Las perplejidades filosóficas surgen en nosotros debido a limitaciones definitivas inherentes a nuestras facultades epistémicas, no porque las cuestiones filosóficas involucren entidades o hechos que sean intrínsecamente problemáticos, peculiares o dudosos" (como se citó en Correcher Valls, 2013, p. 83).

\section{Los Qualia y las Experiencias Subjetivas en el Arte}

C. G. Jung afirma como el inconsciente frente a la consciencia tendría mejores fuentes de información debido a su "espacio-tiempo-relatividad" (Jung, 1996, p. 321), ya que la consciencia sólo dispondría de las percepciones sensoriales, existiendo una percepción sensorial correcta que daría la impresión de que los objetos no penetrarían propiamente en el individuo, sino que éste vería las cosas de manera completamente diferente e incluso a como las ven otros individuos: "De hecho el sujeto percibe las mismas cosas que todo el mundo, pero de ninguna manera se detiene en la pura acción del objeto, sino que se ocupa de la percepción subjetiva desencadenada por el estímulo objetivo" (Jung, 1994, p. 466). Alberto Giacometti parece corroborar este tipo de experiencias confesando como en 1945-46 tuvo una visión, que durante los años posteriores le produjo un cambio profundo en su manera de ver las personas y las cosas a su alrededor. En un cine de París, sintió de repente una 
diferencia entre sus propias percepciones y la visión fotográfica en la pantalla, hablando de esto en una entrevista con Georges Charbonnier en abril de 1957.

T. Nagel parte de la idea de cómo nuestra consciencia se movería entre lo "subjetivo" o interno y lo "objetivo" o externo, planteándose el problema sobre los qualia de como "incorporar el punto de vista subjetivo a la perspectiva objetiva" (Pérez, 2002, p. 76), para este autor "pensar en la realidad exclusivamente desde la perspectiva objetiva es parcial, se obtiene una pintura incompleta de la realidad" (Pérez, 2002, p. 76). E. Pérez de Carrera llama la atención como la ciencia y la tecnología han comprobado que el ser humano está percibiendo desde sus sentidos una porción pequeña del arco electromagnético, por lo que su realidad estaría en un contexto realmente pequeño, afirmando como nuestra definición de la realidad se produciría a partir de nuestra percepción del mundo mediante nuestros sentidos, pero al no tener en cuenta que nuestro cerebro percibe al margen de ellos, estaríamos limitando la apertura de nuestra capacidad sensitiva a todo tipo de experiencias, lo que estaría generando que utilicemos nuestros sentidos de manera anacrónica y disociativamente. Señalando como el ser humano ha intentado generar a lo largo de la historia una asociación intelectual y sensitiva en la consciencia, pero hasta el momento no se habría conseguido, para lograrlo tendríamos que poner nuestra consciencia progresiva en marcha desde la afirmación analítica de la subjetividad:

$\mathrm{Y}$ es el pensamiento subjetivo el primer paso hacia el reconocimiento, y el reconocimiento del mundo sólo puede lograrse utilizando las herramientas que operan en la consciencia; por eso todavía la realidad está sitiada por los radares sensitivos y los medios idiomáticos que facilitan su comprensión, así como los niveles de lectura más elementales de lo manifestado. (Pérez, 2004, pp. 113-114)

E. Pérez de Carrera define la disociación en nuestra sociedad como una falta de pensamiento complejo, si no hay pensamiento complejo, habrá pensamiento lineal que sería un pensamiento dual, afirmando como la Biología moderna ya sabe que nuestra consciencia y lo que configuraría el pensamiento no sería cronológico:

[...] sin embargo todo lo que nos está influyendo en la vida desde la literatura hasta el cine, hasta la forma de contar, hasta la narrativa, hasta el uso de la configuración del idioma, hasta las estructuras holográficas que se van decantando hacía la morfología de las palabras, nos lleva a la disociación, nos conduce a una estructura de la razón basada en toda 
una serie de conocimientos que tienen frontera entre sí. (Pérez, 2009)

D. Chopra y M. C. Kafatos afirman que todo cuanto existe se encuentra encerrado en nuestra subjetividad, el universo visible se interpretaría "como una ínfima parte de la creación original” (Chopra, 2014, p. 218). Así los físicos consideran en la actualidad como "nuestros sentidos seleccionan menos de 1/1.000.000.000 de las ondas y partículas de energía que nos rodean. Vivimos en un magma de energía increíblemente más extenso que el mundo visible" (Chopra, 2014, p. 218).

Según C. G. Jung el individuo sensorial sería en todos los aspectos el reverso de la persona intuitiva, ya que se basaría exclusivamente, en el elemento de la sensación sensorial, su psicología se orientaría hacía el impulso y la sensación, dependiendo por lo tanto totalmente del estímulo real. Mientras que la persona intuitiva tendría sensaciones que no se dirigirían a las sensaciones mismas, sino que éstas serían para el individuo meros puntos de apoyo para la visión, siendo el inconsciente el que realizaría la selección:

No es la sensación fisiológicamente más fuerte la que adquiere el valor principal, sino una sensación cualquiera, que es considerablemente realzada en su valor por la actitud inconsciente del individuo intuitivo. Con ello esa sensación adquiere eventualmente el valor principal y a la consciencia del intuitivo le parece que es una sensación pura. Pero de hecho no lo es. (Jung, 1994, pp. 437-438)

Los artistas del siglo XX y XXI han comenzado a investigar nuevas sensaciones relacionadas con el espacio-tiempo, donde el público jugaría un importante papel, E. Heartney dice como en la obra de estos artistas el espectador dejaría de ser un extraño que se asomaría a otro mundo para sumergirse en la obra artística e incluso a veces interpretar un papel: "Así experimentan la noción de <duración> de Bergson, según la cual el tiempo cesa de sentirse como un flujo lineal y se convierte en un presente omnicomprensivo" (Heartney, 2008, p. 153).

Doug Aitken en su obra en Electric Earth de 1999 (Imagen. 1), descompone la estructura lineal del video y el cine dando un valor preponderante a la percepción del tiempo, utiliza varias pantallas y salas que introducen al espectador en diferentes sensaciones, con el fin de romper con el binomio espacio-tiempo. E. Heartney señala como este artista crearía en el espectador una experiencia fragmentada, acelerada y con múltiples capas. Doug Aitken afirma como esta obra estaría concebida para evocar el aspecto de escenas múltiples de la vida real, diciendo: 
Pasear puede ser una experiencia asombrosa, impulsados por nuestras piernas, encontramos ritmos y tempos. Nuestros cuerpos se mueven en ciclos repetitivos y mecánicos. Perdemos el hilo de nuestras divagaciones. El tiempo se nos escapa; se estira y se condensa. A veces la velocidad de nuestro entorno no está sincronizada con la percepción que tenemos de él. Cuando eso sucede, se crea una especie de zona gris, un estado de flujo que me fascina. (como se citó en Heartney, 2008, p. 158)

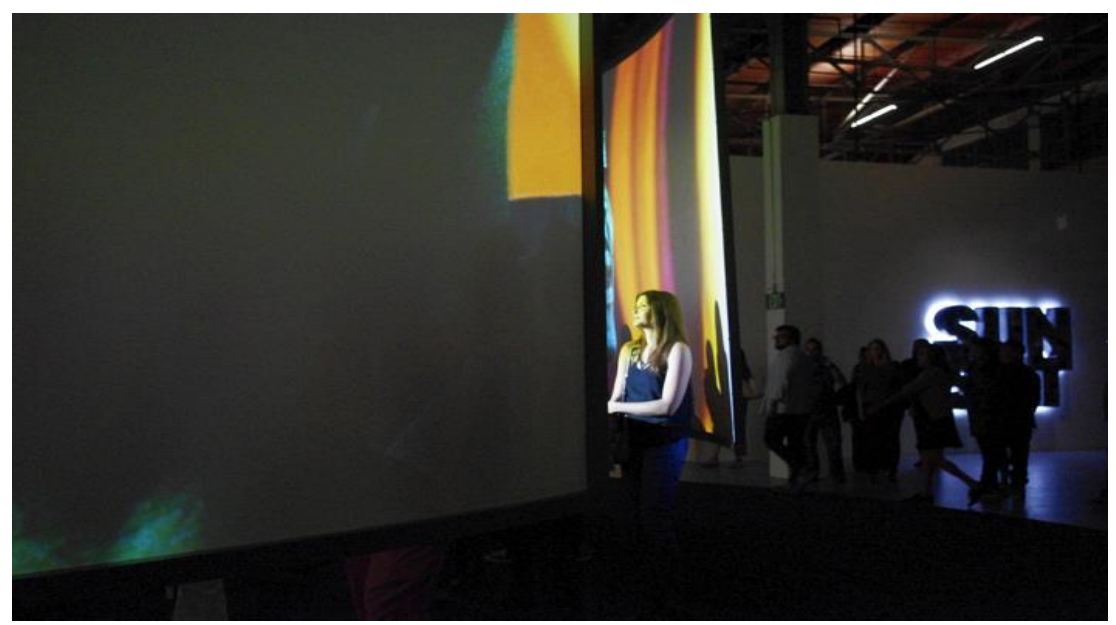

Imagen 1. Aitken, D. (1999). Electric Earth [en línea, Instalación de video de ocho canales y entorno arquitectónico, medidas variables.]

D. Chopra se pregunta si la realidad cuántica no estará situada en nuestros pensamientos, emociones y deseos, diciendo como "Necesitamos de la Naturaleza para liberar nuestra naturaleza. Estamos rodeados por la mejor de las sustancias, es decir, el aire, el sol y la belleza" (Chopra, 2014, p. 136). Pues como decía Mondrian: "Hoy no sólo la belleza pura nos es necesaria, sino que es el único medio que nos manifiesta puramente la fuerza universal que contienen todas las cosas." (como se citó en Vicens, 1973, p. 87) Esta búsqueda de Mondrian estará presente en Andy Goldsworthy que afirma como la naturaleza adquiere una nueva dimensión mediante su interrelación con los fenómenos naturales como el hielo, nieve, tallos de hierba, arena, piedras, zarzas, cañas, hojas, flores, bayas, plumas o el viento, diciendo como en sus procesos creativos tuvo que olvidar su idea de la naturaleza y empezar a aprender "que la piedra es dura y al hacerlo descubrí que es también blanda. 
Arranqué hojas, partí piedras, rasgué plumas [...] para transcender las apariencias y tocar parte de su esencia" (como se citó en Lailach, 2007, p. 48).

Para D. Chopra y M. C. Kafatos el azar y el diseño colaborarían entre sí no sólo en la naturaleza, sino también en nuestros cuerpos y pensamientos, diciendo que si damos al azar su justo valor como ocurre en la teoría cuántica "el cosmos se aproxima a comportarse como una mente... y no sólo eso: como una mente humana" (Chopra y Kafatos, 2017, p. 166). En este sentido W. Rambla señala como todo lo que nos rodea estaría compuesto por materiales que se encontrarían en la naturaleza poseyendo "unas dimensiones estructurales y/o genéticas que permiten el paso de la potencia al acto, de las posibilidades in nuce de lo real a su realidad efectiva" (Rambla, 2008, p. 301). Por lo que este autor deduce que todo se regiría por unas pautas parecidas, nombrando a Christopher Williams que decía en su obra Los orígenes de las formas, como las cosas que construimos "la forma de estas cosas, los materiales utilizados, las leyes que controlan sus dimensiones y las estructuras, no son muy diferentes de aquellas que operan en el mundo natural" (como se citó en Rambla, 2008, p. 301).

\section{La Organización de Nuestra Experiencia por Medio de los Símbolos y los Qualia}

C. G. Jung desde el punto de vista psicológico distingue dos funciones que formarían parte de la aprehensión real del objeto y del crear artístico que serían la "abstracción" y la "empatía". En la primera el objeto estaría a priori dotado de vida y de una actividad autónoma que llevaría a la creación de formas artísticas y al conocimiento del objeto diciendo como el ser humano crearía una imagen abstracta con la que se identifica convirtiéndose "para él en cierto modo en una fórmula liberadora. De esa manera el hombre se enajena de sí mismo y transfiere su vida a su abstracción, en la que en cierto modo se cristaliza" (Jung, 1994, p. 353). Para C. G. Jung la abstracción se separaría del objeto para suprimir el encadenamiento a éste, llevando al sujeto a la creación de formas artísticas y por otro lado al conocimiento del objeto. Mientras que la empatía sería igualmente un órgano de creación artística y de conocimiento, pero esta última tendría lugar sobre una base completamente distinta de la abstracción. La abstracción sería para este autor, por ejemplo, una imagen de la naturaleza concreta mostrando una semejanza asombrosa con la estructura molecular de elementos orgánicos e inorgánicos de la materia. Aquí la intención del artista no participa en el proceso artístico, ya que, éste no es tan libre en su labor creadora como él puede creer, sino que su obra la realiza de 
una forma más o menos inconsciente. La empatía en cambio se basaría en el significado y poder mágico del objeto, ya que, ésta se sustentaría en el significado mágico del sujeto, el cual se apodera del objeto por medio de la “identificación mística. Así como, de un lado, el primitivo está mágicamente influido por la fuerza del fetiche, así de otro, él mismo es también el mago y el acumulador de la fuerza mágica que confiere < carga> al fetiche" (Jung, 1994, pp. 351-352). Kandinsky sigue la misma línea de pensamiento cuando dice que un objeto sería "un ente con vida propia, de la que brotan inevitablemente efectos. El ser humano está constantemente expuesto a estas <irradiaciones psicológicas>, cuyos efectos permanecen en el $<$ subconsciente $>$ o pasan a la conciencia" (Kandinsky, 2010, p. 62).

S. Langer dice como los símbolos que más se acercan al arte serían los del mito, el rito y la metáfora definiendo la obra de arte "como < símbolo de un sentimiento>" (Dorfles, 1967, p. 181). Para esta autora el pensamiento humano tendría la capacidad de crear el símbolo, es decir "sacar de todo dato sensorial una $<$ forma $>$ particular que lo impersonalice" (Dorfles, 1967, p. 181). Esta función simbólica derivaría “de un espontáneo proceso de abstracción que tiende a reconocer el concepto de toda configuración abastecida por nuestra experiencia, a racionalizar después de toda sensación" (Dorfles, 1967, p. 181). Al igual que S. Langer, D. Chopra y M. C. Kafatos señalan como nuestra experiencia del mundo se organizaría por medio de símbolos:

Nosotros humanizamos la realidad, y los qualia que se registran en el cerebro (el dolor, la luz, el hambre, las emociones, etcétera) hacen, a su vez, que el cerebro y el cuerpo evolucionen como representaciones simbólicas. Este bucle retroalimentado no tiene su origen en la biología del cerebro; se origina en la consciencia. La consciencia humana es un canal concreto de salida expresiva para el campo de la consciencia no diferenciado: lo uno crea lo múltiple. (Chopra y Kafatos, 2017, p. 332)

D. Chopra y M. C. Kafatos señalan como los genes, los epigenes y nuestras redes neuronales conservarían y nos recordarían todos los pasos de nuestra evolución, siendo sistemas de registro a las que definen como "firmas simbólicas de redes cuálicas dinámicas. Cada red es autoorganizada, pues no hay dos especies ni dos individuos que funcionen a partir de dos programas cuálicos idénticos. Cada escenario es único; cada uno funciona a través de sus propias posibilidades" (Chopra y Kafatos, 2017, p. 338). En este sentido Dretske y Tye proponen respecto a los qualia la teoría representacional de la mente fenoménica que dice como nuestros estados mentales serían 
representacionales sean estados intencionales o cualitativos, así Dretske haría una distinción entre dos tipos de representaciones mentales entre las que se encuentran las conceptuales o intencionales y las no-conceptuales o fenoménicas que serían las que tendrían que ver con la experiencia sensible, esta tesis representacional identificaría a "los qualia con las propiedades de los objetos que se representan naturalmente, esto es, con aquellas propiedades que la mente está diseñada (biológicamente) para representar sin mediación conceptual" (Pérez, 2002, p. 74).

E. R. Kandel señala como David Hubel y Torsten Wiesel basándose en los trabajos realizados por Kuffler sobre las primeras etapas de la visión, abarcaron otras regiones del cerebro, mejorando "de una manera espectacular nuestra comprensión del procesamiento de la información visual gracias a los diversos relés de esas regiones" (Kandel, 2014, p. 285). Según E. R. Kandel, este trabajo junto con el de Semir Zeki, del University College de Londres, nos ayudan a ver cómo el cerebro construiría las líneas y los contornos necesarios para reconocer los objetos. Según Zeki la línea habría tenido una gran importancia en artistas como Paul Cèzanne, Kazimir Malevich y los cubistas que habrían captado intuitivamente que "en el cerebro del observador, las líneas se someten a un procesamiento muy complejo para generar la impresión de un borde" (Kandel, 2014, p. 285). David Hubel y Torsten Wiesel descubrieron además que las neuronas de la corteza visual primaria reaccionarían de manera ordenada a líneas con una orientación vertical, horizontal u oblicua concreta:

[...] cuando una línea o un borde de color negro giran sobre un eje ante nuestros ojos cambiando lentamente el ángulo de los bordes, se activan neuronas diferentes como repuesta a los distintos ángulos. Algunas neuronas responden cuando el borde está vertical, otras cuando está horizontal y otros cuando está inclinado. Además, al igual que las neuronas de la retina (y del núcleo geniculado lateral), las células nerviosas de la corteza visual primaria responden mejor a las discontinuidades entre oscuridad y claridad. (Kandel, 2014, pp. 289290)

E. R. Kandel afirma que nuestro sistema visual podría elegir y descartar información, algo que no podrían hacer ni las cámaras, ni los ordenadores, llegando a la conclusión de que nuestro ojo no se comportaría como una cámara porque no registraría la imagen de una escena o de un objeto píxel a píxel, ni captaría con exactitud los colores de la imagen: 
[...] cuando una línea o un borde de color negro giran sobre un eje ante nuestros ojos cambiando lentamente el ángulo de los bordes, se activan neuronas diferentes como respuesta a los distintos ángulos. Algunas neuronas responden cuando el borde está vertical, otras cuando está horizontal y otras cuando está inclinado. Además, al igual que las neuronas de la retina (y del núcleo geniculado lateral), las células nerviosas de la corteza visual primaria responden mejor a las discontinuidades entre oscuridad y claridad. (Kandel, 2014, pp. 289290)

Vera Molnar fue la primera artista que en 1968 experimentó un nuevo lenguaje de imágenes a través de un ordenador, creando dibujos basados en el cuadrado y la línea mediante una estricta sistematización abstracta dominada por la probabilidad como vemos en su obra de 1969 titulada Disturbances through overlappings (Imagen. 2), explicando así su proceso de trabajo:

Me imaginaba que tenía un ordenador. Inventaba un programa y entonces, paso a paso, realizaba series sencillas, finitas, pero que concluían en sí mismas, es decir, que no omitían ninguna combinación de formas. Cuando me fue posible, sustituí el ordenador imaginario por uno de verdad. (como se citó en Lieser, 2010, p. 49)

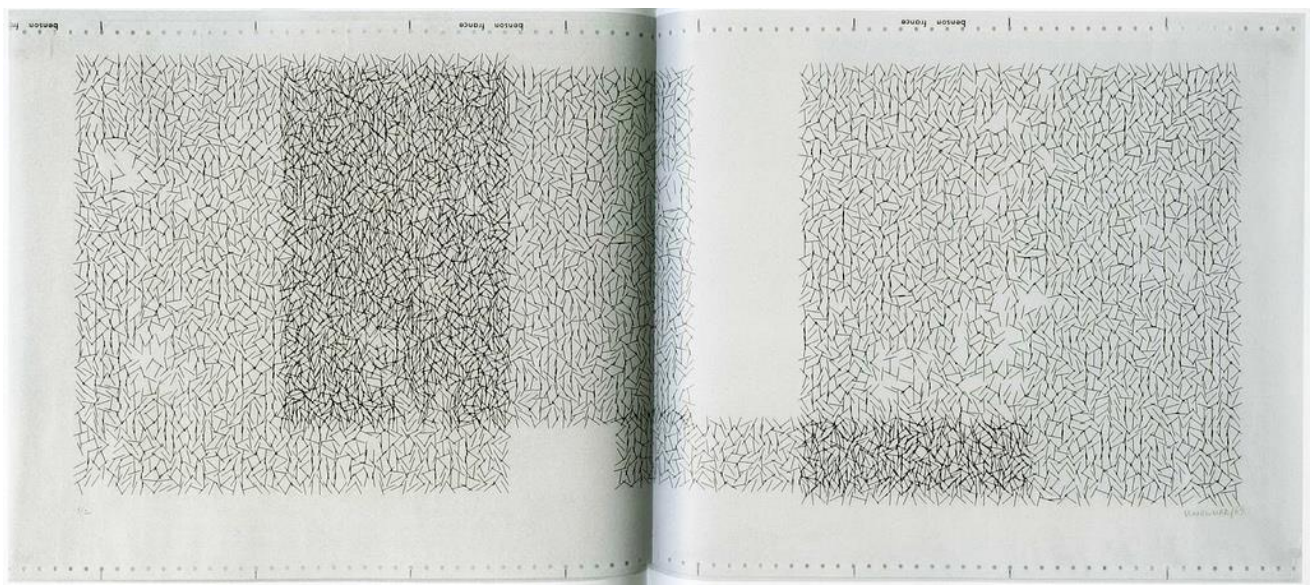

Imagen 2. Molnar, V. (1969). Disturbances through overlappings [en línea, tinta sobre papel, impresión gráfica de computadora; edición 2 de 2; 29 x 77 cm.].

La línea recta sería el componente básico de formas más complejas como el cuadrado que Molnar representa de manera bidimensional en primer plano, los fisiólogos Hubel y Wiesel descubrieron en sus estudios del cerebro visual 
que estas células serían los componentes fisiológicos básicos de la generación neuronal de las formas, descubriendo que las neuronas de la corteza visual primaria no reaccionarían a "cualquier" línea, sino a líneas con una orientación concreta, siendo estas, vertical, horizontal u oblicua. Las células del cerebro sabrían traducir de manera excelente las líneas y los contornos a bordes:

El cerebro integra las líneas simples para formar los bordes que diferencian una figura de su fondo. Siempre que tenemos los ojos abiertos, las células de orientación de la corteza visual primaria construyen los elementos lineales de la escena que tenemos delante. Además, la corteza visual primaria utiliza las regiones inhibidoras de los campos receptoras de esas neuronas para intensificar las líneas de contorno de una imagen. (Kandel, 2014, p. 302)

\section{El Campo de Consciencia Pura y los Qualia}

D. Chopra y M. C. Kafatos afirman como crearíamos nuestra propia realidad perceptual mediante la interacción con la "consciencia pura" que sería el campo básico fundamental de la existencia que no puede ser concebida por nuestro cerebro ya que éste sólo puede conocer la realidad a través de los qualia: "El seno de la creación está más allá del espacio, del tiempo, de la materia y de la energía" (Chopra y Kafatos, 2017, p. 333). Estos autores identifican el estado de pre-creación del universo material con el vacío cuántico, diciendo como la teoría cuántica y las teorías que derivan de ésta, considerarían el vacío como "lleno de "cosas cuánticas"” (Chopra y Kafatos, 2017, p. 63), frente a la física clásica donde este vacío no contendría nada. El vacío cuántico estaría lleno de grandes cantidades de energía que no se manifestaría en el universo mediante la observación con nuestros medios actuales:

[...] el universo sale del vacío cuántico, al menos en cuanto a la disponibilidad de las energías potenciales suficientes. Y tampoco cabe dudar que, si nos remontamos en la historia del universo hasta su fase más temprana, debe intervenir en esta la física del vacío (cuántico). (Chopra y Kafatos, 2017, p. 63)

Para Sri Aurobindo existiría una "consciencia cósmica" (Aurobindo, 1980b, p. 235) o supermental a la que sitúa en el yo de la consciencia universal, donde el "conocedor individual" viviría y estaría "más o menos íntimamente 
unido" (Aurobindo, 1980b, p. 235) y sostendría ante él, el objeto de conocimiento:

El conocedor es un testigo en su observación y esta relación parecería implicar una inigualdad y diferencia, pero la cuestión es que no se trata de una diferencia enteramente separativa y no procura una idea exclusiva de la cosa observada como completamente no-yo, como en la visión mental de un objeto externo. Siempre existe un sentimiento básico de unidad con la cosa conocida, pues si esa unidad no puede haber conocimiento supramental. El conocedor, al llevar el objeto en su universalizado yo de la consciencia como una cosa mantenida frente a su ubicación de visión testimonial, lo incluye en su propio ser más amplio. (Aurobindo, 1980b, pp. 235-236)

Jorge Oteiza dedicará toda su vida a una búsqueda de perfeccionamiento espiritual a través de su obra, diciendo: "El arte está entrando en una zona de silencio (yo terminé en un espacio negativo, en un espacio solo y vacío). En esta Nada el hombre se afirma en su ser (como se citó en Vega, 2005, p. 65). Para Sri Aurobindo el silencio, la entrada en un vacío inmenso e infinito, sería una parte de la experiencia interior espiritual, a la que describe como el "silencio del Espíritu" que no sería el paso a la no-existencia, sino a una existencia más grande. El pensamiento de Jorge Oteiza en su concepción de la materia no difiere mucho de estas ideas, ya que el escultor decía como el vacío sería "la respuesta más difícil y última en el tratamiento y transformación del espacio. El vacío se obtiene, es el resultado de una desocupación espacial, ésta es su energía creada por el escultor, es la presencia de una ausencia formal (como se citó en Rowell, 2005, p. 25).

Sri Aurobindo define el vacío como si el universo fuera sentido en uno mismo o como uno mismo, siendo "una extensión de una consciencia de sí esencial, libre y pura, o es una identificación con el Todo, la extensión o la identificación que constituye un ser cósmico, un individuo universal" (Aurobindo, 2008. p. 164). M. L. von Franz afirma como el "sí-mismo" sería el Hombre Cósmico considerado en Oriente y en algunos círculos gnósticos de Occidente, como una imagen psíquica interior. En la tradición hindú, sería el Purusha que viviría dentro del corazón de todo ser humano y al mismo tiempo llenaría todo el cosmos: "Este Gran Hombre interior redime al individuo conduciéndole, fuera de la creación y sus sufrimientos, otra vez a su esfera originaria. Pero sólo puede hacer esto si el hombre le reconoce y se despierta de su sueño para dejarse conducir" (Franz, 1997, p. 199). 
Y. Michaud señala como el individuo moderno sería un ser frágil que poseería un malestar con su propia identidad, el individuo moderno encauzaría su subjetividad mediante la búsqueda de nuevas sensaciones ligadas al lujo, el placer y la ostentación encontrando a través de estas experiencias su propia identidad a la que define como "la identidad del que tiene esa experiencia" (Michaud, 2015, p. 187), en vez de reconocerse a sí mismo "en la experiencia <de verdad> descubriendo en ella como en un espejo su esencia o su naturaleza" (Michaud, 2015, p. 187), de esta manera la subjetividad se llenaría "de una experiencia buscada como excepción, originalidad y nostalgia. Y así cobra vida, se anima, existe" (Michaud, 2015, p. 187). Para Sri Aurobindo nuestra existencia sería un proceso de autocreación, crecimiento y desarrollo, siendo al principio subconsciente, después semiconsciente y, finalmente, cada vez más y más plenamente consciente de lo que potencialmente somos y llevamos en nuestro interior, definiendo al hobre como un ser mental en la Naturaleza que se distinguiría de las demás criaturas menos desarrolladas por un mayor poder de individualidad, y por haber liberado la consciencia mental. Según este autor la materia no habría podido llegar a ser una cosa animada, si el principio de vida no hubiese estado allí formando parte constitutiva de la materia y emergiendo bajo la forma de "vida-en-la-materia". Ésta última tampoco hubiera podido comenzar a sentir, a percibir, a pensar y a razonar, si de alguna manera el principio mental no hubiera estado detrás de la vida y de la sustancia material. Este principio mental se serviría y se constituiría de la vida y de la sustancia material, usándolas como de base operativa, emergiendo posteriormente a través del fenómeno de una vida y un cuerpo dotados de pensamiento. A esto habría que añadir como también la espiritualidad que emergería en nuestra mente, "es el signo de un poder que es el fundamento y la base constitutiva de la mente, la vida y el cuerpo, y que surge ahora bajo la forma de un ser espiritual encarnado en un cuerpo material viviente y pensante" (Aurobindo, 2002, p. 16). El Espíritu sería algo distinto y más grande que la mente, habiendo emergido en la última fase del proceso evolutivo "porque es el elemento y el factor original de la involución" (Aurobindo, 1999, p. 82). Afirmando como la consciencia y la alegría de ser serían los primeros padres:

Y también los últimos descendientes. La inconsciencia es solamente un intervalo de desvanecimiento de la consciencia o de su oscuro sueño; el dolor y la propia extinción no son más que la alegría de ser huyéndose a ella misma con el fin de encontrarse en otro sitio y de otro modo. (Aurobindo, 1976, p. 31) 
R. Lawlow señala como artistas abstractos como Kandinsky estuvieron influidos por la cosmología geométrica que formaría parte de una doctrina mística de la creación conocida como antropocósmica, una doctrina fundamental en la tradición esotérica de la filosofía desde la antigüedad y que fue actualizada en el siglo XX por Rudolf Steiner, R. A. Schwaller de Lubiez y otros: "El principio primero de esta teoría es que el hombre no es un simple componente de este universo, sino que es más bien a la vez el producto final recapitulador de la evolución y la potencial semilla original a partir de la cual germinó el universo" (Lawlor, 1993, p. 90).

La filosofía antropocósmica representaría la evolución como un intercambio, una inversión continúa entre el eterno hombre cósmico y la humanidad que se encontraría en vías de evolución. Para Rudolf Steiner el ser humano no estaría en realidad separado del mundo, sino que formaría parte de éste, y su conexión con la totalidad del cosmos se encontraría interrumpida no en la realidad, sino para nuestra percepción:

El monismo tal como nosotros lo entendemos, muestra que podemos creer en esa independencia sólo en tanto que el pensamiento se abstiene de ajustar lo percibido a la red del mundo conceptual. Tan pronto como esto tiene lugar, la existencia parcial se revela como mera apariencia debida a la percepción. Su existencia total, contenida en sí dentro del universo, puede hallarla el hombre sólo por medio de la experiencia del pensamiento intuitivo. El pensamiento destruye la apariencia debida a la percepción, e incorpora nuestra existencia individual a la vida del cosmos. La unidad del mundo conceptual, que contiene las percepciones objetivas, comprende también el contenido de nuestra personalidad subjetiva. (Steiner, 1990, pp. 195-196)

\section{Resonancia Mórfica y los Qualia Compartidos}

Para D. Chopra y M. C. Kafatos es importante empezar a concebir una realidad nueva que tendría que ver con un universo nuevo, para ello tendríamos que abordar la realidad como un todo, aunque nuestra "mente limitada no es capaz de hacerlo" (Chopra y Kafatos, 2017, p. 300). La solución de un nuevo renacer del ser humano estaría en el "monismo" que significa "uno, solo o único" que sería la alternativa al dualismo, diciendo que el "rasgo básico de la realidad es la unicidad, no la separación" (Chopra y Kafatos, 2017, p. 301). Nuestras oposiciones estarían construidas por nuestra mente, construiríamos nuestro mundo a base de opuestos que no serían reales, llamando la atención de como nuestra experiencia subjetiva o la empatía que 
sentimos con los demás se produciría por "la resonancia de los qualia compartidos" (Chopra y Kafatos, 2017, p. 333). Para D. Chopra y M. C. Kafatos el universo sería cíclico, un Bing Bang conduciría a otro en un ciclo que no tendría fin, por lo que el estado de precreación, sería en realidad el final del universo que habría existido con anterioridad donde la "sucesión de creaciones conserva una cierta memoria de un ciclo a otro" (Chopra y Kafatos, 2017, p. 68). Estos autores basan estas teorías en nuestra pervivencia de la información:

Si un universo anterior engendró el nuestro, es posible que las constantes y las leyes de la naturaleza se pudieran transmitir de uno a otro en forma de información, sobre todo matemática, pues deben intervenir ciertos aspectos de matemáticas fundamentales, sin que esta manera de pensar llegue a afirmar que las matemáticas son una propiedad física. (Chopra y Kafatos, 2017, p. 72)

R. Sheldrake concibe el universo en evolución, explicando cómo los principios organizativos de "todos los sistemas a todos los niveles de complejidad" habrían evolucionado, originándose con el paso del tiempo, de forma que ninguno de ellos habría existido al principio, es decir cuando se produjo el Bing Bang. De esta forma los cambios sociales y culturales, tendrían que ver con los "campos mórficos", donde se produciría en general un efecto estabilizante y conservador, es decir, no podrían explicar por sí mismos la iniciación del cambio, aunque dichos cambios pueden depender de diversos factores:

El origen de los campos nuevos depende de las circunstancias y de los procesos creativos que no pueden explicarse en términos de repetición. Pero una vez aparecidos los nuevos patrones de actividad, la difusión y la adopción de estas innovaciones pueden facilitarse perfectamente por resonancia mórfica. (Sheldrake, 2006, pp. 380-381)

K. Korotkov llama la atención de como en el siglo XXI se habría introducido la teoría que considera como los cambios epigenéticos de un organismo tendrían que ver con el medio ambiente, demostrándose como el ADN cambiaría por la influencia de las condiciones externar del entorno y como estos cambios se pueden heredar, esta teoría demostraría que "la base molecular del lamarckismo es imposible de negar, particularmente porque estos datos se obtuvieron en el marco del paradigma genético actual" (Korotkov, 2019, p. 177) Para este autor lo más importante de esta cuestión 
es que estos cambios se heredan por las generaciones posteriores además de descubrirse "le existencia de numerosos mecanismos genéticos moleculares, que aseguran la herencia de las características adquiridas... Algunos de estos elementos son sorprendentemente consistentes con la hipótesis visionaria de Darwin sobre Pangénesis y gemmules" (Korotkov, 2019, p. 177).

M. Bautista Pérez señala como la Tierra estaría plenamente interconectada con todo lo que sucedería en el universo, en el cual habría un aumento de la complejidad, siendo una tendencia dominante en su formación, explicando como la consciencia humana debió surgir como consecuencia de ciertas leyes naturales: "Así como los átomos se unen, los cuerpos caen o los imanes se atraen y se repelen, podría suceder que tanto la vida como la consciencia fueran resultados lógicos de ciertas leyes de la naturaleza" (Bautista Pérez, 2015, p. 404). Todo esto se habría ayudado del entorno para activar esta consciencia, además de una reconfiguración de "la estructura neuronal cerebral de modo que pudiese vehicular el nuevo funcionamiento de la consciencia" (Bautista Pérez, 2015, p. 405).

Sri Aurobindo señala como la mente colectiva de la humanidad debe comenzar a admitir las ideas propias de un orden superior, donde los artistas pueden ser los precursores de una nueva etapa. Para que se produzca su llegada, se debe dar un primer signo esencial del inicio de este proceso como el surgimiento y la expansión de la concepción subjetiva de la vida:

La idea del alma, el ser interior, sus poderes, sus posibilidades, su crecimiento, su expresión, y la creación de un medio verdadero, hermoso y favorable para el alma, como la única cosa que tiene una importancia primordial y definitiva. Es preciso que aparezcan los signos precursores de una edad subjetiva en el pensamiento de la humanidad y en su esfuerzo social. (Aurobindo, 2002, pp. 280-281)

La vida en la Tierra sería una red de qualia que nos ayudaría en nuestra evolución donde el siguiente salto que demos tendría que ver con nuestra consciencia pues como dicen D. Chopra y M. C. Kafatos: "El universo consciente abarca el cambio, el no cambio y el estado de cambio en potencia." (Chopra y Kafatos, 2017, p. 291) Estos autores creen que hoy más que nunca la sociedad quiere mejorar y transformarse, por esta razón cada vez más el ser humano estaría aceptando el concepto de universo consciente, el universo estaría creado "para fomentar la expansión de la consciencia en el individuo. Sólo sobre esta base podemos hablar de cambio y de cómo alcanzarlo" (Chopra y Kafatos, 2017, p. 294). 


\section{Conclusiones}

La mente del artista tendría una aspiración de conocer la naturaleza de las cosas mediante los qualia que variarían en función del estado de nuestra consciencia, donde la materia abarcaría también nuestros pensamientos y sueños, ya que viviríamos en un mundo cuántico multidimensional donde nos proyectaríamos en todo lo que experimentamos.

Los qualia que constituirían las cualidades cotidianas de la existencia emanarían de la consciencia, donde el arte puede jugar un importante papel mediante la aplicación de nuestras capacidades perceptivas e intuitivas, generando emociones sensitivas y experiencias de carácter subjetivo tanto en el creador como el receptor de la obra de arte.

Nuestra percepción actual del mundo mediante los sentidos sería anacrónica y disociativa ya que no tendríamos en cuenta que nuestro cerebro percibe al margen de los sentidos, esta situación estaría limitando la apertura de nuestra capacidad sensitiva a todo tipo de experiencias, no obstante a través de la subjetividad y los procesos artísticos se puede romper con la razón, aquí los qualia tienen un importante papel ya que esta experiencia del mundo se organizaría por medio de símbolos que se representarían en el arte, elevando así nuestra consciencia.

La sociedad actual puede cambiar y transformarse gracias a la red de qualia donde la inteligencia artística estaría mejor dispuesta para organizar nuestra vida interior y exterior, abordando la realidad como un todo único en su diversidad, acercándonos así a una consciencia más grande donde los qualia nos ayudarían en esta aventura evolutiva.

\section{Referencias}

Arias Domínguez, A. (2012). "Los qualia: intuiciones y argumentos. Apuntes para una nueva aproximación”. Cuaderno de Materiales, 24, 27-49.

Aurobindo, S. (1976). Ojeadas y pensamiento. Dedalo.

Aurobindo, S. (1980a). Síntesis del Yoga Libro. II. Kier.

Aurobindo, S. (1980b). Síntesis del Yoga. Libro. III, Yoga de Autoperfección. Kier.

Aurobindo, S. (1999). La evolución futura del hombre. Fundación Centro Sri Aurobindo.

Aurobindo, S. (2002). El ciclo humano. Fundación Centro Sri Aurobindo. Aurobindo, S. (2004). La manifestación supramental sobre la Tierra. Fundación Centro Sri Aurobindo. 
Aurobindo, S. (2008). La evolución espiritual. Los seis últimos capítulos de la vida divina. Fundación Centro Sri Aurobindo.

Bautista, M. (2015). La paradoja de Darwin o el enigma del Homo sapiens. Col. Divulgación Científica, Guadalmazán.

Chopra, D. (2014). Curación cuántica. Las fronteras de la medicina mentecuerpo. Gaia Ediciones.

Chopra, D. y Kafato, M. C. (2017). Tú eres el universo. Una nueva alianza entre ciencia y espiritualidad, un nuevo futuro de posibilidades infinitas. Gaia Ediciones.

Correcher Valls Thémata. J. F. (2013). La conciencia irreductible. Los bastiones de Mcginn y Velmans. Revista de Filosofía N47, 79-101.

Dorfles, G. (1967). Símbolo, comunicación y consumo. Serie Ensayo Palabra en el tiempo 35. Lumen.

Erben, W. (1998). Joan Miró 1893-1983. El hombre y su obra. Taschen.

Farouki, N. (1994). La relatividad, Col. Dominos No 6. Debate.

Fontcuberta Llavata, A. (2016). Los supuestos metafísicos del problema difícil de la experiencia consciente en la filosofía de David Chalmers. Facultat de Filosofia i Ciències de l'Educació Departament de Filosofia, Metafísica i Teoria del Coneixement, Lògica i Filosofia de la Ciència i Filosofia Moral.

Franz, M. L. von. (1997). El proceso de individuación en C. G. Jung (ed), El hombre y sus símbolos. Col. Biblioteca Universal no 3, Caralt, pp. 157228.

Gombrich, E. H. (2002). Arte e ilusión. Estudio sobre la psicología de la representación pictórica. Debate.

Heartney, E. (2008). Arte hoy. Phaidon Press Limited.

Itten, J. (2020). El arte del color. Gustavo Gili.

Jung, C. G. (1994). Tipos psicológicos. Edhasa.

Jung, C. G. (1996). Recuerdos, sueños, pensamientos. Col. Biblioteca Breve, Seix Barral.

Kandel, E. R. (2014). La era del inconsciente. La exploración del inconsciente en el arte, la mente y el cerebro. Paidós.

Kandinsky, W. (2010). De lo espiritual en el arte. Col. Paidós Estética n ${ }^{\circ} 24$, Paidós Ibérica.

Kaku, M. (2014). El futuro de nuestra mente. El reto científico para entender, mejorar, y fortalecer nuestra mente. Debate.

Kiran, A. (2004). Sri Aurobindo: La evolución humana y otros escritos. Fundación Centro Sri Aurobindo.

Klee, P. (2007). Teoría del arte moderno. Captus.

Korotkov, K. (2015). La energía de la consciencia. Ediciones Obelisco. 
212 Belén León-Río-Los Qualia y la Experiencia de la Consciencia.

Korotkov, K. (2019). Las misteriosas momias de Nazca. Narración de un testigo presencial. Amazon Fulfillment.

Lailach, M. (2007). Land Art. Taschen.

Lawlor, R. (1993). Geometría Sagrada. Debate.

Lieser, W. (2010). Arte digital. Nuevos caminos en el arte. H. F. Ullmann.

de Barañano, M. (1990). Alberto Giacometti. Dibujo, Escultura, Pintura.

Museo Nacional Centro de Arte Reina Sofía.

Michaud, Y. (2015). El nuevo lujo. Experiencias, arrogancia y autenticidad. Taurus.

Pérez, E. (2004). 49 Respuestas a la aventura del pensamiento, tomo I. Fundación Argos.

Pérez, E. (2009). La Educación en la era planetaria, Primer ciclo sobre complejidad y modelo pedagógico. http://www.tendencias21.net/ciclo/Desde-la-educación-debe-ponerseen-crisis-el-modelo-educativo a29.html

Pérez. D. I. (2002). "Los qualia desde un punto de vista naturalista" BIBLID (65-83)

Rambla, W. (2008). Principales itinerarios artísticos en la plástica y arquitectura del siglo XX: una aproximación a la teoría del arte contemporáneo. Col. Universitas, $\mathrm{n}^{\circ} 28$, Universitat Jaume I.

Rowell, M. (2005). Oteiza, mito y modernidad. Museo Guggenheim de Bilbao.

Sheldrake, R. (2006). La presencia del pasado. Resonancia mórfica y hábitos de la naturaleza. Kairós.

Steiner, R. (1990). La filosofía de la libertad. Antroposófica.

Vega, A. (2005). Oteiza, mito y modernidad. Museo Guggenheim de Bilbao.

Vicens, F. (1973). Arte abstracto y arte figurativo. Col. Biblioteca Salvat Grandes Temas $n^{\circ} 7$, Salvat Editores.

Warr, T. y Jones, A. (2006). El cuerpo del artista. Phaidon.

Wilczek, F. (2016). El mundo como obra de arte. En busca del diseño profundo de la Naturaleza. Crítica.

Wilczek F. (2018). La ligereza del ser. Masa, éter y la unificación de las fuerzas. Crítica. 
Belén León-Río: Profesora Titular del Departamento de Escultura e Historia de las Artes Plásticas. Facultad de Bellas Artes de la Universidad de Sevilla.

Email address: belenleon@us.es

Contact Address: Facultad de Bellas Artes, Departamento de Escultura e Historia de las Artes Plásticas. Calle Laraña n³. CP. 41003. Sevilla. (España) 